\title{
Inflammatory environment created by fibroblast aggregates induces growth arrest and phenotypic shift of human myeloma cells
}

\author{
K. SZABOVA ${ }^{1, *, *}$ I. BIZIKOVA ${ }^{2, \ddagger}$, M. MISTRIK ${ }^{2}$, J. BIZIK ${ }^{1}$ \\ ${ }^{1}$ Cancer Research Institute, Slovak Academy of Sciences, Bratislava, Slovakia; ${ }^{2}$ Department of Hematology and Transfusiology of University \\ Hospital, Hospital of St. Cyril and Method, Bratislava, Slovakia \\ ${ }^{*}$ Correspondence: katarina.szabova@savba.sk \\ ${ }^{*}$ Contributed equally to this work.
}

Received May 14, 2015 / Accepted July 27, 2015

\begin{abstract}
Multiple myeloma (MM) is characterized by accumulation of clonal plasma cells (PCs) predominantly in the bone marrow but tumor cells appear in the circulation in significant numbers as the disease progress. The occurrence of circulating multiple myeloma cells raises question concerning interactions between these cells and stroma of peripheral organs specifically under certain pathophysiological conditions, e.g., inflammation. Therefore, in the present study we exposed three human multiple myeloma cell lines to sterile inflammation produced in a culture dish by clusters of cell-cell contact-activated dermal fibroblasts. We now observed that myeloma cells responded differently to this particular type of stromal cell activation, nemosis. Two cell lines U-266 and LP-1 were minimally affected by the proinflammatory signalling, while the third cell line RPMI 8226 responded with growth arrest and altered expression of three phenotypic markers CD38, CD45, and CD138, indicating dedifferentiation shift of these cells to less mature PC-like phenotype. In a preliminary study we identified a subclone of cells having similar phenotype in 14 out of 23 analysed specimens of MM patients. This set of data indicates that the observed phenomenon might be clinically relevant. Our results emphasize the potential role of activated stromal fibroblasts and subsequent inflammation in altering phenotype of PCs and directing myeloma progression towards dormancy. Given the significant implication of dormant myeloma cells that might serve as a major cellular basis for the relapse, understanding their unique biology and precise elucidation of the underlying molecular mechanisms for the maintenance of quiescence is important. Therefore, we consider this study as a particular contribution to development of experimental model for in vitro studies of cancer dormancy.
\end{abstract}

Key words: human multiple myeloma, dormancy, inflammation, nemosis

Multiple myeloma (MM) is a hematological malignancy resulting from the uncontrolled clonal expansion of malignant plasma cells (PCs) primarily in the bone marrow (BM) [1]. In spite of the fact, that MM is characteristic by prevailed strong tropism for BM in more advanced cases of the disease the significantly increased cell numbers of circulating tumor cells can be encountered in the peripheral blood [2]. Actually, some studies have demonstrated the presence of circulating PCs in more than $70 \%$ of patients with MM [3]. Very recent study by Paiva et al. [4] elegantly showed that circulating myeloma tumor cells, as defined by the presence of peripheral blood clonal PCs, might be even a powerful prognostic marker in MM. However, in some patients with MM, the PCs proliferation escapes the BM microenvironment influences and it results in extramedullary disease (EMD), which can constitute the most prominent clinical feature of the disease [5]. It is supposed, that EMD represents an entity in which the clonal PCs have lost their dependence on the BM milieu for growth due to altered expression of their homing and adhesion molecules [6]. Thus, in cases of extramedullary MM, the tumor cells do not only home to the BM niches but colonize the other organs, including subcutaneous sites, liver, kidney, gut, lungs, and rarely central nervous system [7]. The most common sites for EMD at diagnosis were skin and soft tissues [8]. Clinical data concerning onset of EMD indicate that inflammatory process could facilitate migration of myeloma cells and constitute a reservoir of dormant myeloma cells able to proliferate what is consequently leading to a relapse [9]. Therefore, these observations raise the question to what extent circulating PCs can be affected and prone to gain additional 
phenotypical changes in peripheral organs, as a consequence of certain processes, e.g., inflammation.

Inflammation is a pathophysiological response to infection or tissue damage [10]. In general, inflammation is frequently observed in cancer patients receiving treatment modalities with various modes of action. Transient inflammatory reactions have been reported in subgroup of patients with MM during lenalidomide plus dexamethasone therapy [11]. The inflammatory response is characterized by coordinate activation of various signalling pathways including NF- $\kappa \mathrm{B}$ in resident tissues [12]. Moreover, several studies confirmed the central role of constitutive NF- $\mathrm{kB}$ activation in the progression and relapse of MM $[13,14]$.

Epidemiological studies showed that incidence of MM is age related, predominantly affecting elderly patients [15]. However, accumulating evidence indicates that aging is associated with a chronic low-level inflammation, termed sterile-inflammation. Sterile-inflammation is a form of pathogen-free inflammation caused by mechanical trauma, ischemia, stress or environmental conditions, such as ultraviolet radiation [16]. The release of bioactive cytokines from necrotic cells occurs with sterile inflammation and enhances the inflammatory response. This pathophysiological state is frequently accompanied by massive production and secretion of a variety of cytokines and growth factors by activated mesenchymal stromal cells [17].

Previously, we introduced and characterized a new biological way of mesenchymal cell activation called nemosis [18]. Nemosis, which is triggered solely by cell-cell contacts, is programmed process of cell activation and subsequent death, the most distinctly observed in human dermal fibroblasts [19]. These activated fibroblasts are characterized by production of inflammation-associated cytokines and growth factors, e.g., IL-1, IL-6, IL-8, IL-11, LIF, GM-CSF, as well as, COX-2 related-secretion of prostaglandins [20]. In order to functionally evaluate the myeloma cells' capacity to respond to stromal inflammation, we utilized an in vitro model of the nemosis-induced inflammation of fibroblasts in a threedimensional culture setting, where analysed MM cells were cocultured with the fibroblast spheroids. Therefore, the aim of this study was to identify phenotypic and/or cell proliferation parameter of three human myeloma cell lines exposed to the particular conditions mimicking acute sterile inflammation in peripheral organs, e.g., skin. We consider this experimental setting as biologically relevant since certain extramedullary MM are presented in patients as a large subcutaneous mass [6]. In the case of ongoing inflammation in such a body part the MM cells might be intimately affected by the pertinent signal molecules.

In summary, we showed in the present study that multiple myeloma cells exposed to conditions of sterile inflammation responded differently to this stimulus. Although, the U-266 and LP- 1 cell lines were affected minimally by the inflammatory conditions, dramatic growth and phenotypic changes were detected in RPMI 8226 cells. The growth arrest of the latter cell line was accompanied with entry to quiescent state and acquisition of phenotype similar to less differentiated PCs. These novel gained phenotypic parameters were applied to search for similar cell population within the bone marrow specimens of MM patients. We identified a subpopulation of myeloma cells with comparable phenotypic pattern which was clearly distinguishable from the core MM population in 14 out of 23 MM patients tested, so far. This set of data outlines the possibility the observed phenomenon might have clinical implication. We assume the established three-dimensional co-cultivation system can contribute to identification of the underlying mechanisms of dormant MM cell biology.

\section{Materials and methods}

Antibodies. Antibodies used for flow cytometry (FACS) were: anti-CD20-VioBlue (130-094-167, Miltenyi Biotec, Bergish Gladbach, D), anti-CD38-FITC, (A07778, Beckman Coulter, Marseille, F), anti-CD45-VioGreen (130-096-906, Miltenyi Biotec), anti-CD138-PE (130-081-301, Miltenyi Biotec).

Cell cultures. Human dermal fibroblasts MUF 7/1 established from neonatal foreskin were kindly provided by Dr. Miroslav Pirsel, Cancer Research Institute, Bratislava, Slovakia and in experiments were used from passages 5 to 15. Analysed human MM cell lines: U-266 [21], RPMI 8226 [22] and LP-1 [23] were purchased from the German Collection of Microorganisms and Cell Cultures (DSMZ), Leibniz Institute, Germany. All MM cell lines and MUF 7/1 strain fibroblasts were cultured in RPMI 1640 medium supplemented with $10 \%$ foetal bovine serum, $50 \mathrm{IU} / \mathrm{mL}$ streptomycin and $50 \mu \mathrm{g} / \mathrm{mL}$ penicillin (all from Life Technologies, Gibco, Carlsbad, CA).

Formation of fibroblast aggregates (spheroids). Spheroid formation was initiated as described previously [19]. Briefly, U bottom 96-well plates (TPP, Trasadingen, Switzerland) were treated with $0.8 \%$ SeaKem LE agarose (Lonza, Rockland, ME) prepared in sterile water to form a thin film of non-adhesive surface. MUF 7/1 fibroblasts were detached from culture dishes by trypsin/EDTA, and a single cell suspension $\left(4 \times 10^{4} \mathrm{cells} / \mathrm{mL}\right)$ was prepared in complete RPMI 1640 culture medium. Thereafter, $250 \mu \mathrm{L}$ aliquots were seeded into individual wells, and the plates were incubated at $+37^{\circ} \mathrm{C}$ in $5 \% \mathrm{CO}_{2}$ atmosphere.

Coculture of myeloma cell lines and fibroblast spheroids. For the coculture and nemosis stimulation experiments, the myeloma cells were cocultured, at starting concentration $5 \times 10^{2}$ cells/well, for various time-periods with 24-hr-preformed fibroblast spheroids. For the estimation of growth curves, cell numbers of each type of myeloma cells, were evaluated by cellcounting using a Bürker chamber. Phenotype characteristics of stimulated myeloma cells were performed with aliquots of the cocultured cells after their separation from multicellular spheroids by gravity based on the much higher density of multicellular aggregates as compared to hematopoietic cells.

Cell cycle analysis. For cell cycle analysis, MM cell lines were cocultivated during $96 \mathrm{~h}$ with 24 -hr-preformed fibroblast 
spheroids and afterwards separated from fibroblast clusters by sedimentation. Isolated myeloma cells were then washed twice with PBS and fixed in cold $\left(-20^{\circ} \mathrm{C}\right)$ absolute ethanol during $2 \mathrm{~h}$. After fixation cells were washed twice with PBS and then incubated with propidium iodide $(40 \mu \mathrm{g} / \mathrm{mL})$ and RNAse A $(10 \mu \mathrm{g} / \mathrm{mL})$ at room temperature during $40 \mathrm{~min}$. Stained samples were directly analysed by FACS.

Flow cytometry. Analysed MM cell lines were cocultivated with spheroids for indicated time points and after removal of spheroids by differential sedimentation were processed for FACS analysis. Cells were washed twice with PBS and then incubated on ice with specific antibodies according to manufacturer's recommendations. FACS analysis was performed by FACS Canto II flow cytometer (BD Biosciences, San Jose, CA). Data were analysed using BD FACSDiva version 6.1.3 (BD Biosciences, San Jose, CA) and FCS Express version 3 (DeNovo Software, San Jose, CA).

A
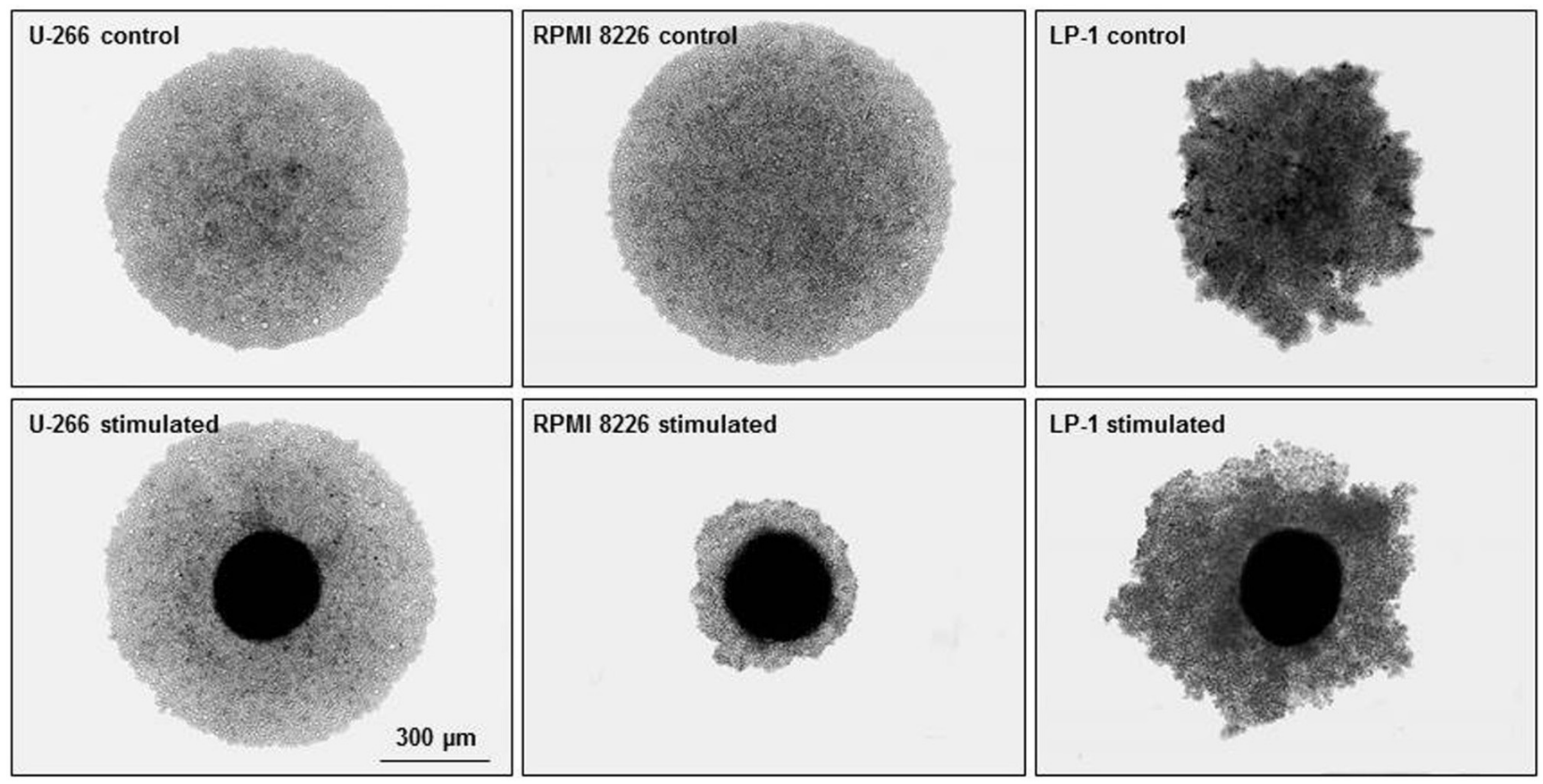

B
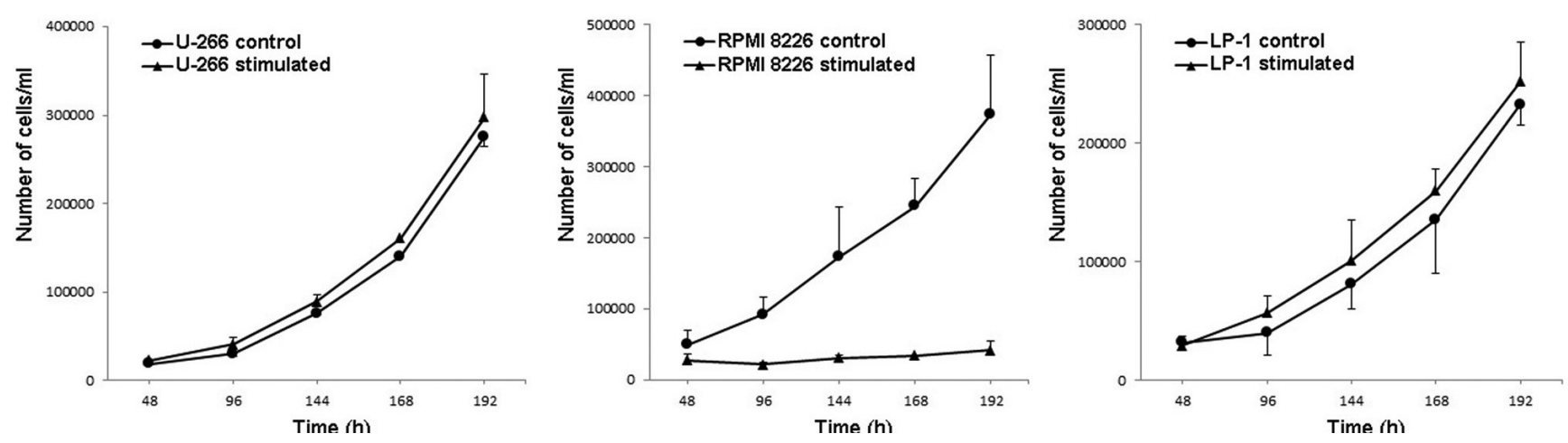

Figure 1. Coculture of analysed multiple myeloma cell lines with activated dermal fibroblasts MUF 7/1. (A) Phase contrast microscopy of control cultures of the neat cell lines and those grown as cocultures in the presence of a spheroid after $168 \mathrm{~h}$ of incubation in a 96 well plate. The fibroblasts $\left(10^{4} /\right.$ well) were allowed to form spheroids during $24 \mathrm{~h}$ and afterwards individual myeloma cell lines $\left(5 \times 10^{2} /\right.$ well $\left.^{2}\right)$ were added. Dense structure in the centre matches the spheroid and a halo-like structure around represents the myeloma cells. Scale bar is $300 \mu \mathrm{m}$. (B) Comparison of proliferation kinetics of the multiple myeloma cell lines during stimulation by activated fibroblasts in the same experimental settings as above. Cell numbers were estimated in $48 \mathrm{~h}$ intervals. Points, means from five values of cell numbers per ml; bars, FSE. 
Patient samples. Overall, 23 patients with symptomatic MM, 9 newly diagnosed cases and 14 patients with relapse/refractory disease, as well as, 5 healthy donors were studied. Bone marrow samples were collected at Department of Hematology and Transfusiology of University Hospital, Hospital of St. Cyril and Method, Bratislava, Slovakia after informed consent was given by each individual patient, according to the local ethical committee. BM mononuclear cells were isolated by density gradient on Ficoll-Pague ${ }^{\mathrm{TM}}$ Plus (GE Healthcare Bio-Sciences AB, Uppsala, S). Three-color multiparametric flow cytometry was performed on the isolated cells after staining.

\section{Results}

In order to mimic situation where myeloma cells are exposed to specific inflammatory conditions occurring in peripheral organs, e.g., skin, we principally adopted methodological approach in which dermal fibroblasts were activated by clustering in $3 \mathrm{D}$ culture and formed spheroids were subsequently placed into coculture with the tested myeloma cells. Previously, we have shown that the contact-activated fibroblast cells are characterized by massive induction of genes that are exclusively exhibiting proinflammatory activity [20]. The unique feature of this system is that sterile inflammatory conditions are gained in culture dish without addition of any exogenous stimulus as an inducer of the inflammation. It is important to stress this fact since analysed myeloma cells, when placed into a coculture, are affected only by a spectrum of proinflammatory signal molecules produced by activated fibroblasts. In the present study we analysed effect of activated human dermal fibroblasts MUF 7/1 on growth and phenotypic characteristics of $3 \mathrm{MM}$ cell lines. The tested myeloma cells were cocultured for various time-periods with 24-hr-preformed fibroblast spheroids starting at an 1:20 myeloma cell:fibroblasts ratio. Fig. 1a represents a phase contrast microscopy view of neat individual MM cell lines, as well as, their appearance as coculture with the spheroid after $168 \mathrm{~h}$ of incubation. It is evident that nemotic fibroblasts creating inflammatory conditions induced a dramatic inhibition of the RPMI 8226 cells which responded with discernible growth arrest, whereas the U-266 cells showed only marginal, if any inhibition. In the LP-1 cells, only a very modest growth stimulation was apparent. The inflammatory-arrested proliferation of the responder RPMI 8226 cells persisted throughout the study (Fig. 1b). This set of our results suggests that translation of dermal fibroblasts-nemosis signalling with huge production of proinflammatory signalling molecules might be largely determined by the phenotype and especially receptor-expression profile of the target MM cells.

Further, we analysed the MM cell lines' cell-cycle phase distribution in order to characterize more precisely the status of inflammation responsive RPMI 8226 cells. Fig. 2 demonstrates the DNA histograms comparison of control and stimulated cultures after $168 \mathrm{~h}$. In response to inflammatory conditions, the U-266 and LP- 1 cells retained very similar cell-cycle characteristics when compared to control unstimulated cells, what is actually in accordance with growth pattern presented in Fig. 1b. In contrary, the same conditions induced $40 \%$ increase in accumulation of RPMI 8226 cells in the G0G1 phase. These cells shift away from the $\mathrm{S}$ and $\mathrm{G} 2$ phases in comparison with cell cycle distribution of RPMI 8226 cells in control culture, what may indicate that stimulated cells entered the state of dormancy. Based on the literature data, neoplastic dormancy can be achieved by two distinct ways: either each cancer cell arrests its cell cycle or the whole neoplasm exhibits balanced growth/cell death rates [24]. In order to verify the fact that observed growth arrest of RPMI 8226 cells is not a consequence of increased cell death occurrence in the cocultures, which simply balance the growth of the cell population, we assessed
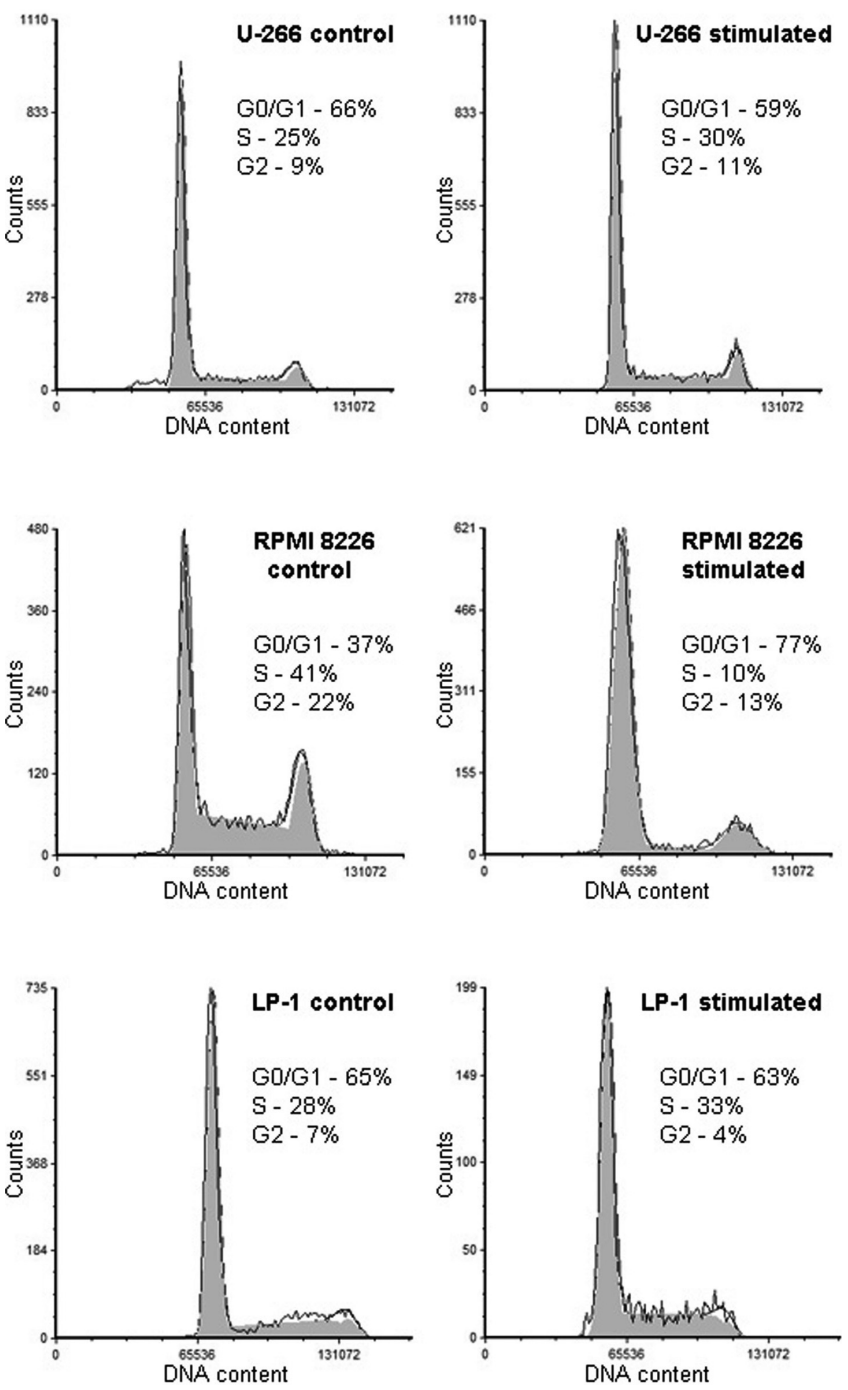

Figure 2. Comparison of DNA histograms of individual multiple myeloma cell lines. Related percentage of cells as divided into cell cycle G0/G1, S and G2 phases of the cell cycle for control cultures and cells after cocultivation with activated MUF $7 / 1$ fibroblasts for $168 \mathrm{~h}$ are shown. The plots represent data from one of three independent experiments. 
A
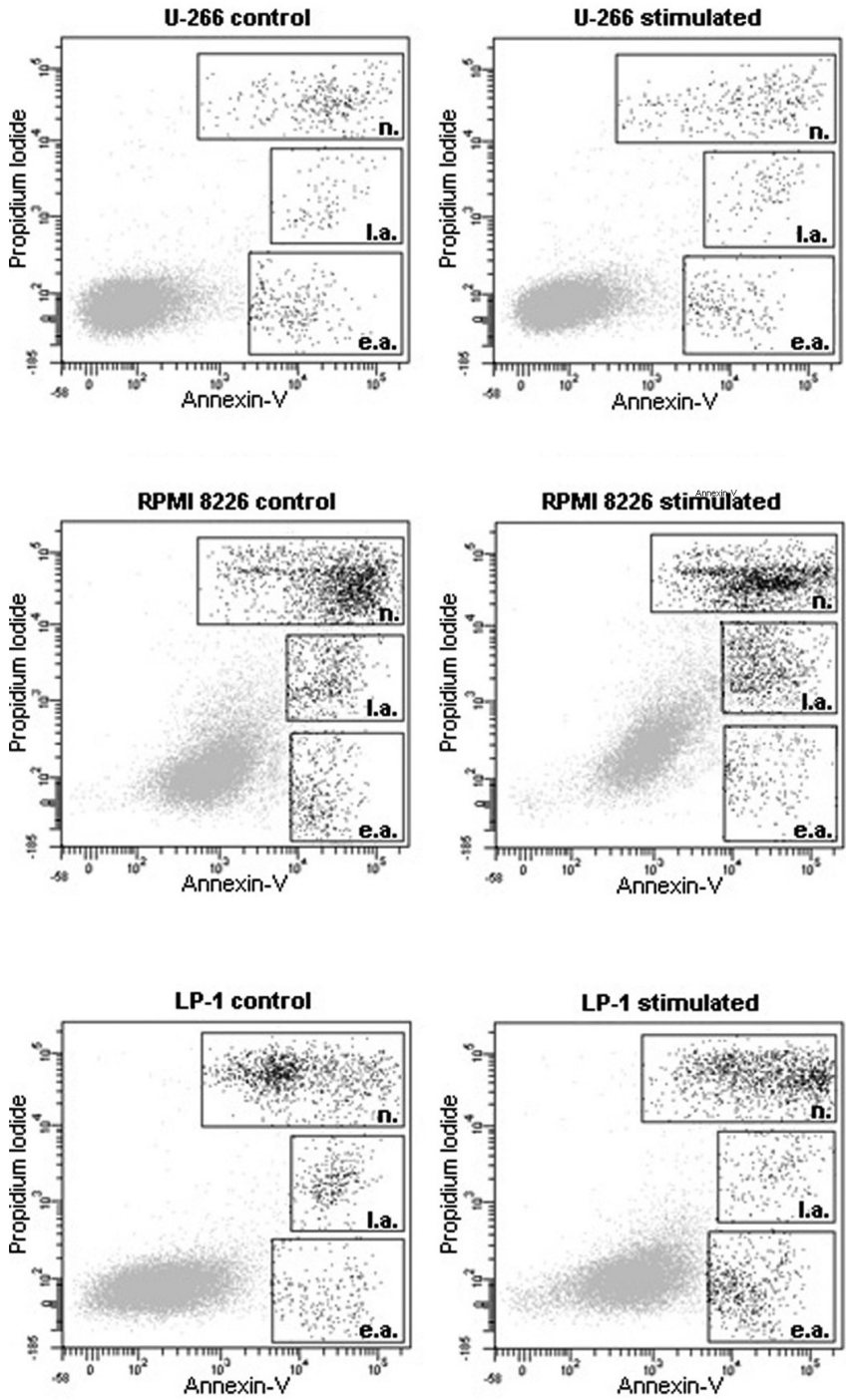

the apoptotic and necrotic cell numbers in individual cell cultures. Employing simultaneous staining of the cell lines with annexin- $\mathrm{V}$ and propidium iodide we estimated percentage of early apoptotic, late apoptotic and necrotic cells (Fig. 3). The lowest degree of cell death, representing 3\% of total cell numbers, was evident for the U-266 cell line with equally affecting control cell culture (2.9\%) and that exposed to inflammatory conditions (3\%). Higher incidence of cell death was detected in LP-1 cell line where control cell culture exhibited evidence of cell death $9.1 \%$ versus $13.1 \%$ in stimulated cell culture. RPMI 8226 cell cultures contained the highest percentage of cells indicating process of cell death of all three cell lines tested. While cell death positivity in the RPMI 8226 control cultures was $16.2 \%$, for the cells affected by inflammatory conditions it was up to $20.9 \%$. Still the observed $4 \%$ difference between control and stimulated cell cultures is similar for the RPMI 8226 and the LP-1 cell line, as well. It might be concluded that inflammation-induced growth arrest in the RPMI 8226 cell line is combination of cellular and tumor dormancy. This assumption is based on the observation that $77 \%$ of cells are arrested in G0G1 phase of cell cycle and the rest 23\% of the whole cell population remain in S and G2 phase. The latter phase endures tumor dormancy.

Healthy bone marrow plasma cells are $\mathrm{CD} 38^{+} \mathrm{CD} 138^{+}$ $\mathrm{CD} 19^{+} \mathrm{CD} 45^{+} \mathrm{CD} 56{ }^{-}$while $\mathrm{MM}$ tumor cells are $\mathrm{CD} 38^{+} \mathrm{CD} 138^{+}$, $90 \%$ are $\mathrm{CD} 19^{-}, 99 \%$ are $\mathrm{CD} 45^{-}$or $\mathrm{CD} 45^{\text {low }}$, and $70 \%$ are $\mathrm{CD}^{+} 6^{+}$[25]. Our previous results showed that leukemic cells achieved altered phenotypic characteristics due to regulatory signals coming from stromal microenvironment only when they are growth arrested [20]. Therefore, we performed phenotypic characterization of tested myeloma cell lines after exposure to the inflammatory conditions with focus on the RPMI 8226 cells. Overall, we analysed expression of selected 13 cell surface markers which used to be employed for characterization of MM-cell phenotype, e.g., CD19, CD20, CD28, CD38, CD45, CD49e, CD49d, CD54, CD56, CD117, CD138, CD184, HLA-DR [4]. Noticeable differences were detected in

B
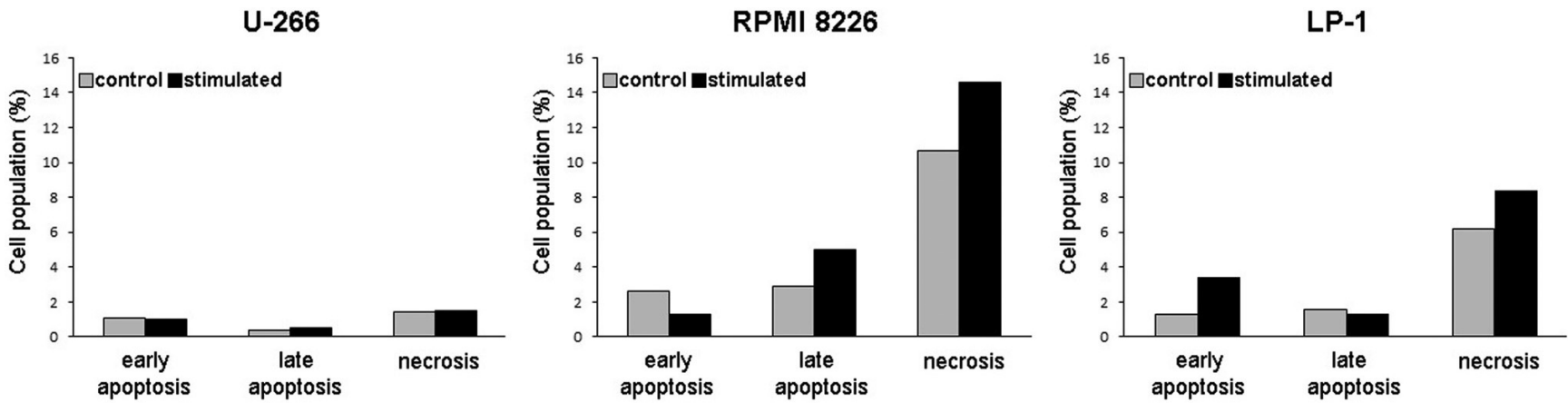

Figure 3. Estimation of apoptotic and necrotic cell populations in cultures of analysed myeloma cell lines. Control cultures and those isolated from cocultures with fibroblast spheroids after $168 \mathrm{~h}$ of incubation were stained with annexin- $\mathrm{V}$ and propidium iodide and afterwards the percentage of early apoptotic (e.a.), late apoptotic (l.a.) and necrotic (n.) cells was assessed by FACS. The upper plot (A) shows representative FACS data of one of three independent experiments and in the lower chart $(\mathrm{B})$ the bars point out percentage of individual cell populations. 
expression of three CD markers, specifically CD38, CD138, CD45, and to certain extent CD20, as well. Fig. 4 illustrates, that the CD38 expression decreased in all three cell lines after exposure to inflammatory signalling achieved in coculture. Certain decrease of the CD138 marker expression was seen in the U-266 cells and increase in the LP-1 cells. The most significant down regulation of the CD138 was evident in the RPMI 8226 cells. Expression level of CD45 stayed almost unchanged in the U-266 and LP-1 cells, while positivity for this marker was significantly increased in the RPMI 8226 cells. Detectable increase was observed also for the CD20 marker in the RPMI 8226 but expression of this marker decreased at very marginal level in the U-266 cell line. Taken together, this set of data indicates that the growth arrested RPMI 8226 cells gained the most dramatically altered phenotype pattern when compared to the other 2 tested cell lines. The achieved modified phenotype of RPMI 8226 cells parallels less differentiated pattern of plasma cells [26].

In vitro obtained data represented challenge for a search of the identified subclone of MM cells in clinical specimens. Therefore, we performed preliminary screening of a randomly selected panel of bone marrow samples routinely taken for phenotyping of MM patients either newly diagnosed cases or relapsed. In total we analysed 23 patients, where 9 patients
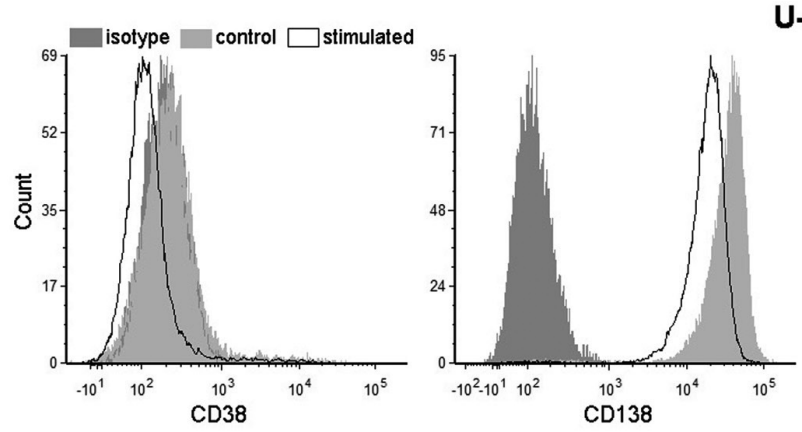

$\mathrm{U}-266$
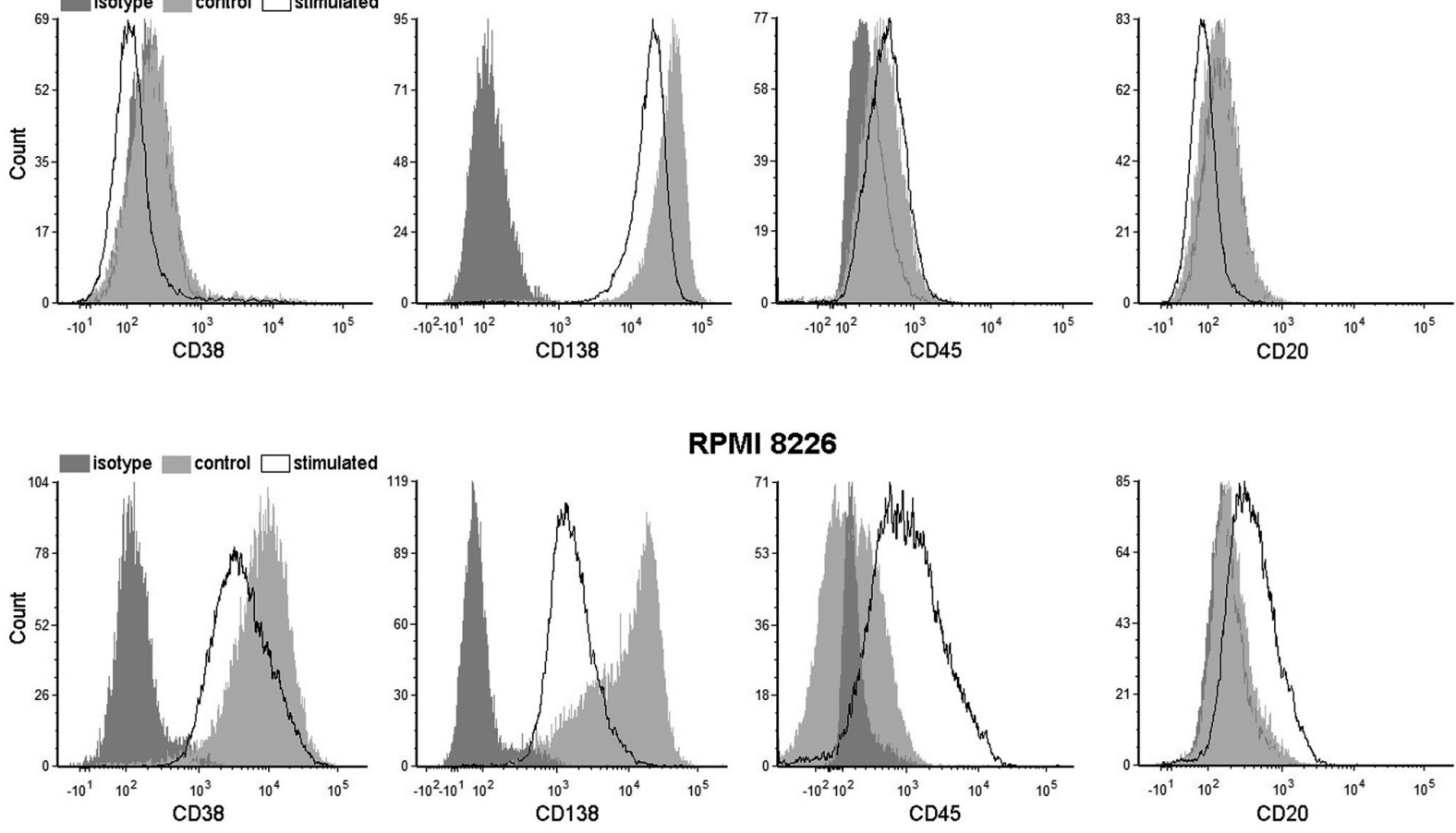

RPMI 8226
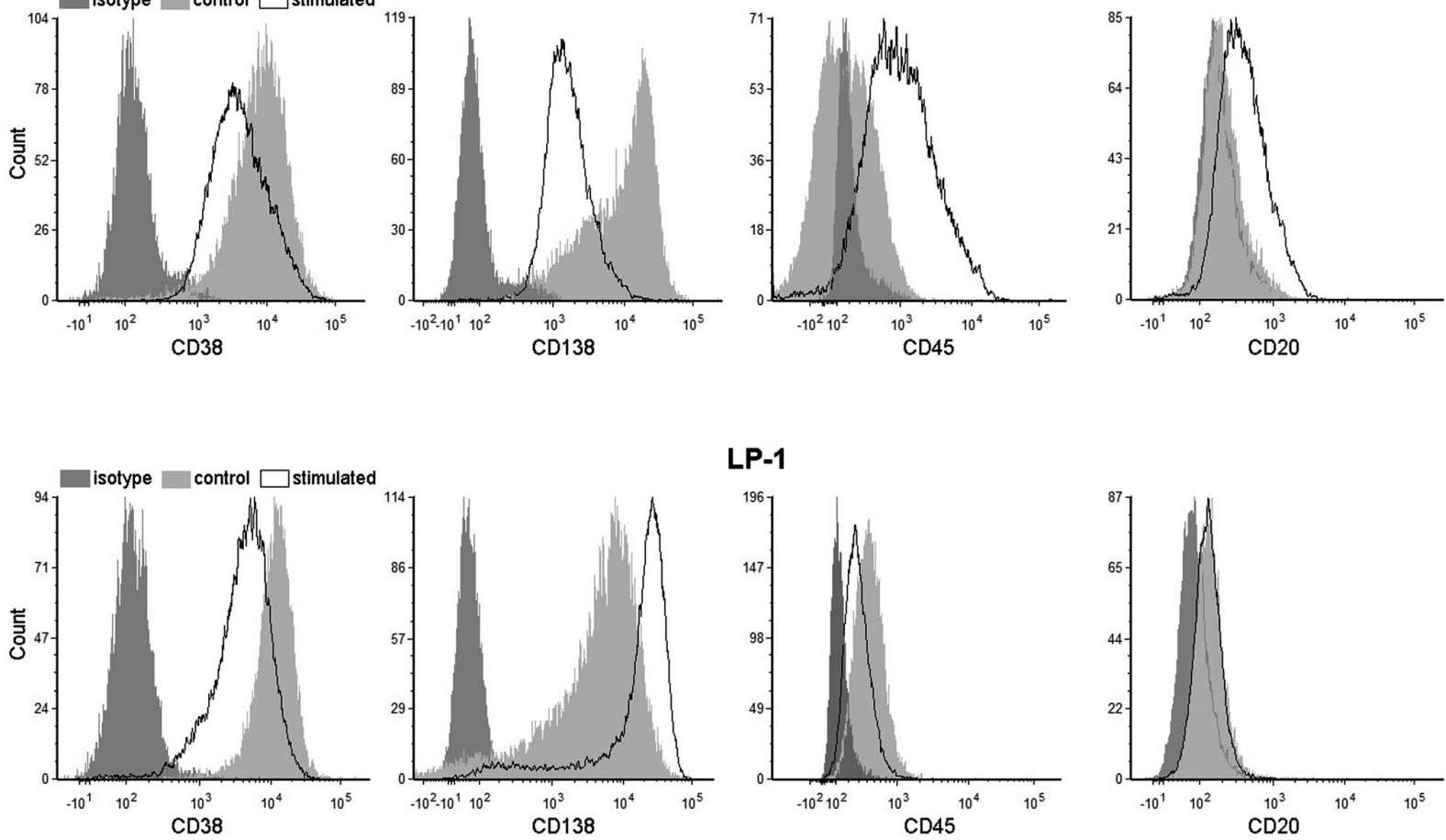

\section{LP-1}
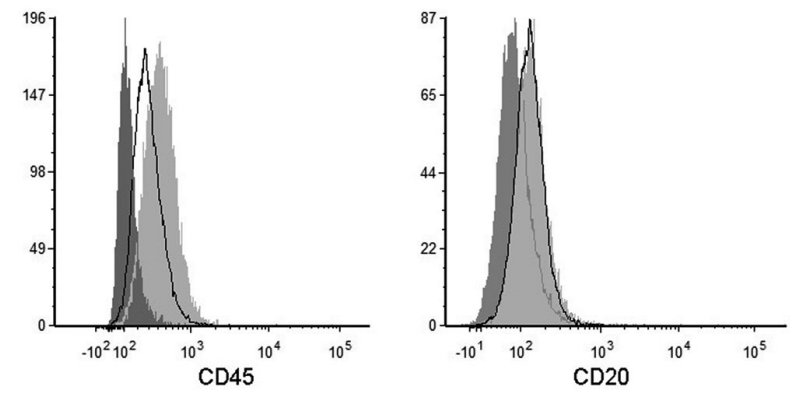

Figure 4. FACS analysis of the myeloma cell lines for expression of specific phenotypic markers after stimulation with inflammatory conditions. In the myeloma cells cocultured with MUF 7/1 fibroblast spheroids during $168 \mathrm{~h}$ were observed noticeable changes in four phenotypic markers (CD38, CD138, CD45 and CD20) in comparison to control cells without stimulation. The most dramatic changes were detected in RPMI 8226 cell line as showed on the histograms. Isotype-matched negative control is represented by dark peak, control cultures by grey peak and the signal for stimulated cells is outlined by black line. 
were newly diagnosed and 14 had actively relapsing disease. We also tested 5 specimens obtained from healthy donors but there were no indications for the appearance of this type of subclone. In the group of newly diagnosed patients, in 6 out of 9 cases, we were able to evidently match the subpopulation of cells which was less positive for CD38 and CD138 but had enhanced expression of CD45 than the core population of MM cells as it is seen in Fig. 5 (Patient No. 3). For comparison, there is shown a dot plot image of one out of three patients (Patient No. 7) being certainly negative for this subpopulation. In the group of relapsed patients, 8 out of 14 cases were found to be positive as it is documented for the Patient No. 15. This analysis complements and signifies the in vitro observation on the existence of a specific subpopulation of cells within MM malignancy which might be relevant biological phenomenon in manifestation of the MM.
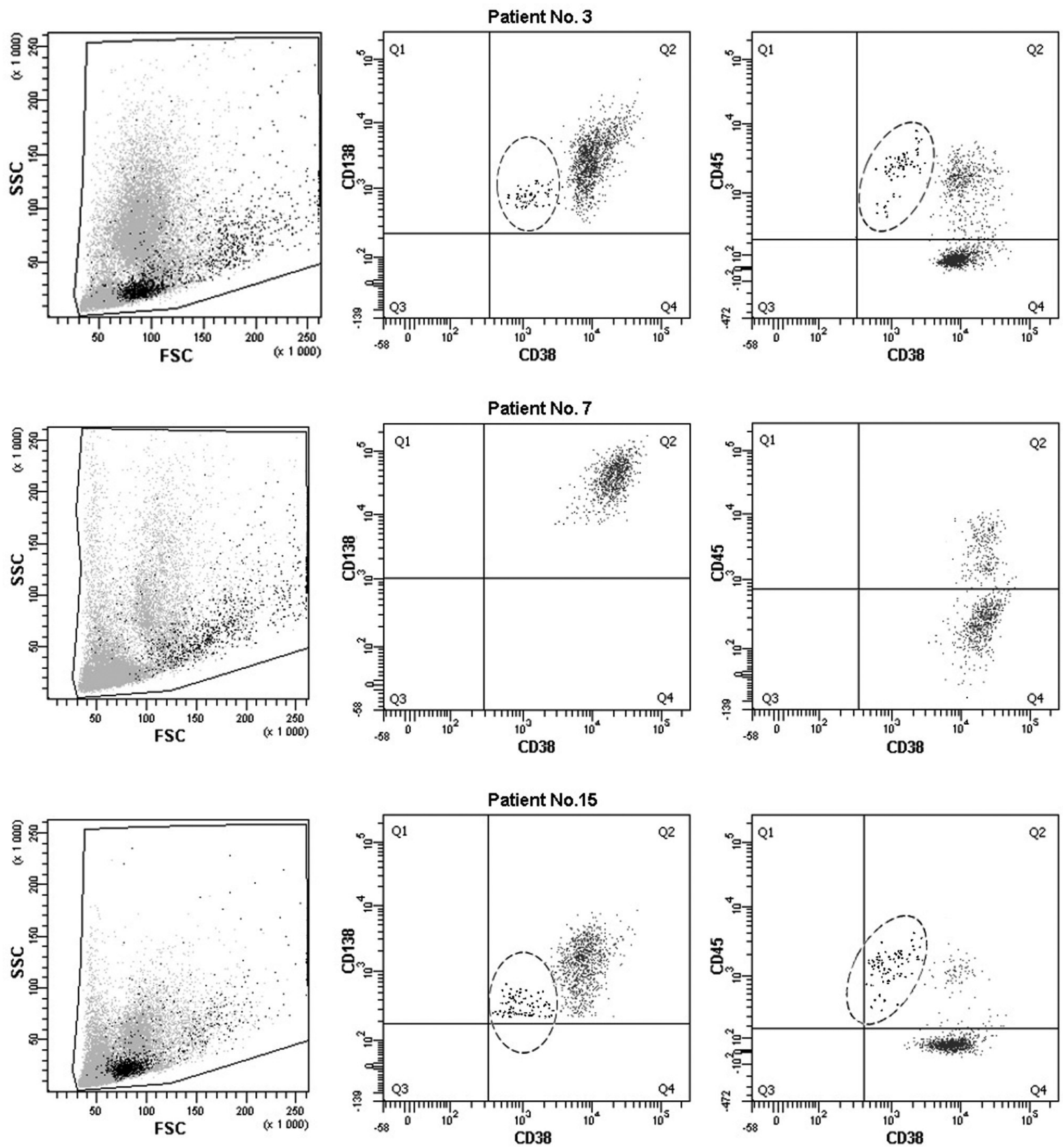

Figure 5. Flow cytometric dot plots demonstrating presence of specific subpopulation (marked with the oval) of myeloma cells in patients' bone marrow samples. Three-color multiparametric flow cytometry was performed on the isolated cells after staining with antibodies to CD38, CD45 and CD138. This picture shows representative specimens of bone marrow from the newly diagnosed patients No.3, No.7 and the patient No.15 in relapse. 


\section{Discussion}

The progress made in cancer research during last two decades led to postulation of eight hallmarks of cancer which are acquired during development and progression of human tumors [27]. In this revisited conceptual review of the cancer characteristics a new feature, the need for a local inflammation response, was included. Inflammation state present within tumor microenvironment is considered to be even a central characteristic which can promote several of these hallmarks through creation of a growth factor-rich milieu and production of bioactive molecules. MM is one of the malignancies that are associated with inflammatory microenvironments $[28,29]$. In the present study we observed that inflammation might extensively inhibit mitogenic capability of myeloma cells as it was clearly demonstrated in the case of the RPMI 8226 cell line. The effect seems not to be universal since the growth of two other analysed myeloma cell lines, U-266 and LP-1, was minimally influenced. This set of our results suggests that translation of dermal fibroblasts-nemosis signalling with huge production of proinflammatory molecules might be largely determined by the phenotype of the targeted myeloma cells and especially receptor-expression profile which are capable to transmit proinflammatory signalling. This finding is not surprising since $\mathrm{MM}$ is highly biologically heterogeneous with significant variability among patients in terms of clinical features, response to therapy and overall survival [30]. Certain characteristics of in vivo manifested heterogeneity for MM are maintained and preserved in derived myeloma cell lines [31]. The most fundamental feature of cancer cells represents their ability to sustain proliferation. As a neat culture the RPMI 8226 cells exhibited the highest growth potential within the panel of analysed cell lines. On the basis of our earlier findings on profuse production of HGF by nemosis-activated skin fibroblasts [18] one would expect that the growth of RPMI 8226 cells will be more busted in the coculture. The RPMI 8226 cells are well documented in the literature to express functionally active receptor tyrosine kinase c-Met on their surface via which the HGF triggered mitogenic signal is transmitted [32]. Notably, the fact that the myeloma cells are growth arrested in the presence of excess amounts of HGF emphasize a prevalence and vast potency of proinflammatory signalling as a regulation mechanism to drive receptive target cells to quiescence in this experimental setting. Indoleamine 2,3-dioxygenase produced by MM microenvironment was described to have strong inhibitory properties on myeloma cell growth and survival [33]. Taking into account this possibility we analysed presence of this enzyme in conditioned medium of the nemotic fibroblasts but no activity of the enzyme was detected (data not shown). In this context, additional potential signalling molecule for analysis is LIF. This cytokine is abundantly produced during nemosis and was originally identified as a growth inhibitor with a positive effect on differentiation of leukemic cells [34]. At the present level of analysis we are not able to denote a signal molecule produced by nemotic fibroblasts which is principally causing dormant status of the RPMI 8226 cells. Since the co-culture conditions allow a full range of biological interplay, including complex paracrine signalling and cell contacts, the effect on myeloma cells will be probably synergistic effect of several stimuli. Therefore, we plan to extend our analysis and focus on differences of intracellular signalling pathways associated with growth arrest and differentiation, e.g., caspase-3, Bcl-2, Bcl-2XL, Bax, ERKs, p38 and JNK in the next experiments.

Evidently, expansion of the RPMI 8226 cell population in coculture was blocked but only $77 \%$ of cells achieved cellular dormancy being arrested in G0G1 phase of cell cycle. The rest of cells was not completely inactive, having characteristics of tumor mass dormancy where the cell population exhibits balanced growth/apoptosis rate. This fact points out how extremely complex is the interplay between proinflammatory signalling and cellular response in a given population of neoplastic cells.

Cell cycle arrest represents a critical signal for cells to trigger the program of differentiation and terminally differentiated cells are typically post mitotic [35]. Therefore, we performed phenotypic analysis of all tested myeloma cell lines after exposure to nemosis, with focus on RPMI 8226 cells. As expected, the most significant phenotypic changes were detected in RPMI 8226 cell line. These cells underwent de-differentiation when subjected to fibroblast nemosis and gained phenotype reminiscent to less differentiated plasma cells. Our results are in accordance with observation made by the group of Dezorella et al. [36]. They showed that incubation of multiple myeloma cells with bone marrow-derived mesenchymal stromal cells led to reduction of expression of plasma cell differentiation markers CD38 and CD138, as well [36]. Moreover, we also observed significant increase of CD45 expression after exposure of these cells to nemosis. Similarly, Yaccoby [37] described decreased expression of CD38, CD138 and increased expression of CD45 in primary human multiple myeloma cells after their prolonged cultivation with human osteoclasts. Our results supported by the above mentioned publications suggest that multiple myeloma cells possess plasticity, what allow them to undergo process of de-differentiation and enter dormancy-like state. Today, there is growing evidence that MM have a certain degree of plasticity that might be responsible for expression of a wide range of multi-lineage markers or acquisition of stem cell properties [38]. Deregulation of mechanisms regulating plasticity may lead to de-differentiation which may represent a key mechanism for generation of tumor-initiating cells in cancer [38,39].

Considerable progress has, however, been achieved in the treatment of MM in the past decade with survival improvement in newly diagnosed MM patients after introduction of novel effective drugs [40]. In spite of this fact, almost all MM patients still relapse after treatment which emphasizes that the majority of patients with MM have persistent levels of residual disease [41]. Currently, multiparameter flow cytometry and PCR are two the most routinely used methods to estimate the 
minimal residual disease (MRD) [42]. Normal PCs characteristically express CD138 and strongly express CD38. The features of aberrant PCs observed in patients with MRD include slightly decreased expression of CD38 and the absence of CD45 [43]. In our study, we identified a subpopulation of MM cells that exhibited similar phenotypic parameters as RPMI 8226 cells exposed to nemosis in samples derived from bone marrow of multiple myeloma patients. Using FACS-gating on dot plots by double staining (CD38 vs. CD138 and CD38 vs. CD45) we found a subpopulation of MM cells exhibiting decreased expression of both core PCs markers, the CD38 and CD138, and enhanced expression of CD45. Based on our in vitro experiments we assume, that this subpopulation of MM cells may represent a potential dormant MM cells. To confirm this hypothesis, it is necessary to further analyse cell cycle status of this subpopulation, as well as, expression of additional phenotypic markers, e.g., CD19, CD56. Moreover, at the present level of investigation it is not possible to give an answer to what extent the dormant PCs subpopulation participate at MRD manifestation during the disease burden. Since this subpopulation of MM cells was also found in specimens of newly diagnosed patients it indicates that they do not emerge solely as a consequence of certain treatment. In the light of the findings presented here, further investigation is warranted to determine to what extent the presence of such subset of MM dormant cells in widen series of clinical specimen would be a solid negative prognostic marker in patients with $\mathrm{MM}$ in the term to predict its refractory potential.

Till today, the mechanisms associated with tumor dormancy are only poorly understood, in part because of the difficulties with isolation of dormant tumor cells [44]. One of the critical limitations in this field is that molecular markers of dormancy are not now known, as well as, that there is a lack of versatile experimental model that will mimic tumor cell dormancy and enable their detailed analysis.

Collectively, this study demonstrated the basic molecular characteristics of the in vitro cellular model system which could be a useful tool for a better understanding of the molecular mechanisms of dormant myeloma cells appearance in this type of malignancy.

Acknowledgements: The authors thank Mrs Alena Linekova for her skillful technical assistance. The project was supported by VEGA grant 2/0124/13 from Grant Agency of Slovak Republic.

\section{References}

[1] PALUMBO A, ANDERSON K. Multiple myeloma. N Engl J Med. 2011; 364: 1046-1060. http://dx.doi.org/10.1056/ NEJMra1011442

[2] GARCIA-SANZ R, ORFAO A, GONZALEZ M, TABERNERO MD, BLADE J et al. Primary plasma cell leukemia: clinical, immunophenotypic, DNA ploidy, and cytogenetic characteristics. Blood 1999; 93: 1032-1037. PMID: 9920853.
[3] NOWAKOWSKI GS, WITZIG TE, DINGLI D, TRACZ MJ, GERTZ MA et al. Circulating plasma cells detected by flow cytometry as a predictor of survival in 302 patients with newly diagnosed multiple myeloma. Blood 2005; 106: 2276-2279. http://dx.doi.org/10.1182/blood-2005-05$\underline{1858}$

[4] PAIVA B, PAINO T, SAYAGUES JM, GARAYOA M, SANSEGUNDO L et al. Detailed characterization of multiple myeloma circulating tumor cells shows unique phenotypic, cytogenetic, functional, and circadian distribution profile. Blood 2013; 122: 3591-3598. http://dx.doi.org/10.1182/blood2013-06-510453

[5] BLADE J, DE LARREA CF, ROSINOL L. Extramedullary involvement in multiple myeloma. Haematologica 2012; 97: 1618-1619. http://dx.doi.org/10.3324/ haematol.2012.078519

[6] BLADE J, FERNANDEZ DE LARREA C, ROSINOL L, CIBEIRA MT, JIMENEZ R et al. Soft-tissue plasmacytomas in multiple myeloma: incidence, mechanisms of extramedullary spread, and treatment approach. J Clin Oncol. 2011; 29: 3805-3812. http://dx.doi.org/10.1200/JCO.2011.34.9290

[7] GHOBRIAL IM. Myeloma as a model for the process of metastasis: implications for therapy. Blood 2012; 120: 20-30. http://dx.doi.org/10.1182/blood-2012-01-379024

[8] USMANI SZ, HEUCK C, MITCHELL A, SZYMONIFKA J, Nair B et al. Extramedullary disease portends poor prognosis in multiple myeloma and is over-represented in high-risk disease even in the era of novel agents. Haematologica 2012; 11: 1761-1767. http://dx.doi.org/10.3324/ haematol.2012.065698

[9] ROSINOL L, FERNANDEZ DE LARREA C, BLADE J. Extramedullary myeloma spread triggered by surgical procedures: an emerging entity? Acta Haematol. 2014; 132: 36-38. http://dx.doi.org/10.1159/000354833

[10] MEDZHITOV R. Origin and physiological roles of inflammation. Nature 2008; 454: 428-435. http://dx.doi.org/10.1038/ $\underline{\text { nature } 07201}$

[11] HARADA T, OZAKI S, ODA A, FUJI S, NAKAMURA S et al. Association of Th1 and Th2 cytokines with transient inflammatory reaction during lenalidomide plus dexamethasone therapy in multiple myeloma. Int J Hematol. 2013; 97: 743-748. http://dx.doi.org/10.1007/s12185-0131321-0

[12] LAWRENCE T. The nuclear factor NF-kappaB pathway in inflammation. Cold Spring Harb Perspect Biol. 2009; 1: a001651. http://dx.doi.org/10.1101/cshperspect.a001651

[13] ANNUNZIATA CM, DAVIS RE, DEMCHENKO Y, BELLAMY W, GABREA A. Frequent engagement of the classical and alternative NF-kappaB pathways by diverse genetic abnormalities in multiple myeloma. Cancer Cell 2007; 12: 115-130. PMID: 17692804 http://dx.doi.org/10.1016/j. ccr.2007.07.004

[14] KEATS JJ, FONSECA R, CHESI M, SCHOP R, BAKER A. Promiscuous mutations activate the noncanonical NFkappaB pathway in multiple myeloma. Cancer Cell 2007; 12: 131-144. PMID: 17692805 http://dx.doi.org/10.1016/j. $\underline{\mathrm{ccr} \cdot 2007.07 .003}$ 
[15] PALUMBO A, BRINGHEN S, MATEOS MV, LAROCCA A, FACON T et al. Geriatric assessment predicts survival and toxicities in elderly myeloma patients: an International Myeloma Working Group report. Blood 2015; 125: 2068-2074. http://dx.doi.org/10.1182/blood-2014-12-615187

[16] ROCK LK, LATZ E, ONTIVEROS F, KONO H. The sterile inflammation response. Annu Rev Immunol. 2010; 28: 321-342. http://dx.doi.org/10.1146/annurev-immunol030409-101311

[17] BALKWILL FR, MANTOVANI A. Cancer-related inflammation: Common themes and therapeutic opportunities. Semin Cancer Biol. 2012; 22: 33-40. http://dx.doi.org/10.1016/j. semcancer.2011.12.005

[18] KANKURI E, CHOLUJOVA D, COMAJOVA M, VAHERI, A, BIZIK J. Induction of hepatocyte growth factor/scatter factor by fibroblast clustering directly promotes tumor cell invasive $\neg$ ness. Cancer Res. 2005; 65: 9914-9922. http://dx.doi. org/10.1158/0008-5472.CAN-05-1559

[19] BIZIK J, KANKURI E, RISTIMAKI A, TAIEB A, VAPAATALO $\mathrm{H}$ et al. Cell-cell contacts trigger programmed necrosis and induce cyclooxygenase-2 expression. Cell Death Differ. 2004; 11: 183-195. http://dx.doi.org/10.1038/sj.cdd.4401317

[20] KANKURI E, BABUSIKOVA O, HLUBINOVA K, SALMENPERA P, BOCCACCIO $\mathrm{C}$ et al. Fibroblast nemosis arrests growth and induces differentiation of human leukemia cells. Int J Cancer 2008; 122: 1243-1252. http://dx.doi.org/10.1002/ ijc. 23179

[21] NILSSON K, BENNICH H, JOHANSSON SG, PONTEN J. Established immunoglobulin producing myeloma (IgE) and lymphoblastoid (IgG) cell lines from an IgE myeloma patient. Clin Exp Immunol. 1970; 7: 477-489. PMID: 4097745

[22] MATSUOKA Y, MOORE GE, YAGI Y, PRESSMAN D. Production of free light chains of immunoglobulin by a hematopoietic cell line derived from a patient with multiple myeloma. Proc Soc Exp Biol Med. 1967; 125: 1246-1250. http://dx.doi.org/10.3181/00379727-125-32327

[23] PEGORARO L, MALAVASI F, BELLONE G, MASSAIA M, BOCCADORO $\mathrm{M}$ et al. The human myeloma cell line LP-1: a versatile model in which to study early plasma-cell differentiation and c-myc activation. Blood 1989; 73: 1020-1027. PMID: 2784066

[24] CREA F, NUR SAIDY NR, COLLINS CC, WANG Y. The epigenetic/noncoding origin of tumor dormancy. Trends Mol Med. 2015; 21: 206-211. http://dx.doi.org/10.1016/j. molmed.2015.02.005

[25] RAJA KR, KOVAROVA L, HAJEK R. Review of phenotypic markers used in flow cytometric analysis of MGUS and MM, and applicability of flow cytometry in other plasma cell disorders. Br J Haematol. 2010; 149: 334-351. http://dx.doi. org/10.1111/j.1365-2141.2010.08121.x

[26] BORRELLO I. Can we change the disease biology of multiple myeloma? Leuk Res. 2012; 36 Suppl 1: S3-12. http://dx.doi. org/10.1016/S0145-2126(12)70003-6

[27] HANAHAN D, WEINBERG RA. Hallmarks of cancer: the next generation. Cell 2011; 144: 646-674. http://dx.doi. org/10.1016/j.cell.2011.02.013
[28] MANTOVANI A, GARLANDA C. Inflammation and multiple myeloma: the Toll connection. Leukemia 2006; 20: 937-938. http://dx.doi.org/10.1038/sj.leu.2404229

[29] LEE H, KONG SY, SOHN JY, SHIM H, Youn HS et al. Elevated red blood cell distribution width as a simple prognostic factor in patients with symptomatic multiple myeloma. Biomed Res Int. 2014; 2014: Article ID 145619. http://dx.doi. org/10.1155/2014/145619

[30] GONSALVES WI, RAJKUMAR SV, GUPTA V, MORICE WG, TIMM MM et al. Quantification of clonal circulating plasma cells in newly diagnosed multiple myeloma: implications for redefining high-risk myeloma. Leukemia 2014; 28 : 2060-2065. http://dx.doi.org/10.1038/leu.2014.98

[31] DREXLER HG, MACLEOD RA. History of leukemia-lymphoma cell lines. Hum Cell. 2010; 3: 75-82. http: //dx.doi. org/10.1111/j.1749-0774.2010.00087

[32] MOSCHETTA M, BASILE A, FERRUCCI A, FRASSANITO MA, RAO L et al. Novel targeting of phospho-cMET overcomes drug resistance and induces antitumor activity in multiple myeloma. Clin Cancer Res. 2013; 19: 4371-4382. http://dx.doi.org/10.1158/1078-0432.CCR-13-0039

[33] PFEIFER S, SCHREDER M, BOLOMSKY A, GRAFFI S, FUCHS D et al. Induction of indoleamine-2,3 dioxygenase in bone marrow stromal cells inhibits myeloma cell growth. J Cancer Res Clin Oncol. 2012; 138: 1821-1830. http://dx.doi. org/10.1007/s00432-012-1259-2

[34] LENTZSCH S, CHATTERJEE M, GRIES M, BOMMERT K, GOLLASCH H et al. PI3-K/AKT/FKHR and MAPK signaling cascades are redundantly stimulated by a variety of cytokines and contribute independently to proliferation and survival of multiple myeloma cells. Leukemia 2004; 18: 1883-1890. http:// dx.doi.org/10.1038/sj.leu.2403486

[35] SIMONATTO M, LATELLA L, PURI PL. DNA damage and cellular differentiation: more questions than responses. J Cell Physiol. 2007; 213: 642-648. http://dx.doi.org/10.1002/ jcp. 21275

[36] DEZORELLA N, PEVSNER-FISHER M, DEUTSCH V, KAY $S$, BARON S et al. Mesenchymal stromal cells revert multiple myeloma cells to less differentiated phenotype by the combined activities of adhesive interactions and interleukin-6. Exp Cell Res. 2009; 315: 1904-1913. http://dx.doi.org/10.1016/j. yexcr.2009.03.016

[37] YACCOBY S. The phenotypic plasticity of myeloma plasma cells as expressed by dedifferentiation into an immature, resilient and apoptosis-resistant phenotype. Clin Cancer Res. 2005; 11: 7599-7606. http://dx.doi.org/10.1158/1078-0432. CCR-05-0523

[38] HAJEK R, OKUBOTE SA, SVACHOVA H. Myeloma stem cell concepts, heterogeneity and plasticity of multiple myeloma. Br J Haematol. 2013; 163: 551-564. http://dx.doi. org/10.1111/bjh.12563

[39] MARJANOVIC ND, WEINBERG RA, CHAFFER CL. Cell plasticity and heterogeneity in cancer. Clin Chem. 2013; 59: 168-179. http://dx.doi.org/10.1373/clinchem.2012.184655

[40] RAJKUMAR SV. Treatment of multiple myeloma. Nat Rev Clin Oncol. 2011; 8: 479-491. http://dx.doi.org/10.1038/ nrclinonc. 2011.63 
[41] MAgRANGEAS F, AVET-LOISEAU H, GOURAUD W, LODE L, DECAUX O et al. Minor clone provides a reservoir for relapse in multiple myeloma. Leukemia 2013; 27: 473-481. http://dx.doi.org/10.1038/leu.2012.226

[42] HART AJ, JAGASIA MH, KIM AS, MOSSE CA. et al. Minimal residual disease in myeloma: are we there yet? Biol Blood Marrow Transplant. 2012; 18: 1790-1799. http://dx.doi. org/10.1016/j.bbmt.2012.05.009
[43] MAILANKODY S, KORDE N, LESOKHIN AM, LENDVAI AM, HASSOUN $\mathrm{H}$ et al. Minimal residual disease in multiple myeloma: bringing the bench to the bedside. Nat Rev Clin Oncol. 2015; 12: 286-295. http://dx.doi.org/10.1038/ nrclinonc.2014.239

[44] VESSELLA RL, PANTEL K, MOHLA S. Tumor cell dormancy: an NCI workshop report. Cancer Biol Ther. 2007; 6: 1496-504. http://dx.doi.org/10.4161/cbt.6.9.4828 